\title{
Nuclear Translocation of the p75 Neurotrophin Receptor Cytoplasmic Domain in Response to Neurotrophin Binding
}

\author{
José M. Frade \\ Instituto Cajal, Consejo Superior de Investigaciones Científicas, E-28002 Madrid, Spain
}

The intracellular domain of the $\mathrm{p} 75$ neurotrophin receptor $\left(\mathrm{p} 75^{\mathrm{ICD}}\right)$ can be released by $\gamma$-secretase in response to the previous activation of $\alpha$-secretase by phorbol esters. However, ligand-dependent release of $\mathrm{p} 75^{\mathrm{ICD}}$ has yet to be described. We show here that nerve growth factor can induce the release of $\mathrm{p} 75^{\mathrm{ICD}}$ and facilitate its translocation to the nucleus in a $\gamma$-secretase-dependent manner. This effect was observed in RN22 schwannoma cells cultured under serum-free conditions, as well as in Schwann cells, and it was mimicked by other neurotrophins, such as brain-derived neurotrophic factor or neurotrophin-3. Unlike other known examples of regulated intramembrane proteolysis, ligand-dependent release of $\mathrm{p} 75^{\mathrm{ICD}}$ did not need the previous activation of $\alpha$-secretase. These results suggest that nuclear translocation of $\mathrm{p} 75^{\mathrm{ICD}}$ may represent a novel neurotrophin-mediated signaling pathway.

Key words: $\alpha$-secretase; $\gamma$-secretase; $\mathrm{p} 75^{\mathrm{NTR}}$; neurotrophin; nuclear translocation; regulated intramembrane proteolysis

\section{Introduction}

The neurotrophin family is composed of nerve growth factor (NGF), brain-derived neurotrophic factor (BDNF), neurotrophin-3 (NT3) and neurotrophin-4/5. These molecules act as ligands for the Trk neurotrophic receptor tyrosine kinases, as well as for the common p75 neurotrophic receptor ( $\left.\mathrm{p} 75^{\mathrm{NTR}}\right)$, a member of the tumor necrosis factor (TNF) receptor family (LópezSánchez and Frade, 2002). In recent years, a number of signaling pathways have been described that mediate the response of ligand binding to $\mathrm{p} 75^{\mathrm{NTR}}$ (López-Sánchez and Frade, 2002). More recently, the activation of $\alpha$-secretase by phorbol esters was shown to provoke the release of the intracellular domain of $\mathrm{p} 75^{\mathrm{NTR}}$ $\left(\mathrm{p} 75^{\mathrm{ICD}}\right)$ in a number of cell lines, including RN22 schwannoma cells (RN22-SCs) (Jung et al., 2003; Kanning et al., 2003). However, evidence for ligand-mediated intramembrane cleavage of p $75^{\text {NTR }}$ has yet to be presented. In this article, we show that endogenously expressed $\mathrm{p} 75^{\mathrm{ICD}}$ can be released and translocated to the nucleus in response to both NGF and other neurotrophins. Moreover, it seems that the release of $\mathrm{p} 75^{\mathrm{ICD}}$ is independent of metalloproteinase-dependent shedding of the $\mathrm{p} 75^{\mathrm{NTR}}$ ectodomain.

\section{Materials and Methods}

Materials. All of the chemical reagents were purchased from Sigma (St. Louis, MO) unless otherwise stated. The rabbit polyclonal antisera (9992) against $\mathrm{p} 75^{\mathrm{ICD}}$ and against the extracellular domain of $\mathrm{p} 75^{\mathrm{NTR}}$ $\left(\mathrm{p} 75^{\mathrm{ECD}}\right.$ ) (9651; diluted 1:800 for immunocytochemistry; diluted 1:2000

Received June 9, 2004; revised Dec. 24, 2004; accepted Dec. 27, 2004.

This work was supported by grants from Fundación "la Caixa," Fondo de Investigaciones Sanitarias, and Comunidad Autónoma de Madrid. I am grateful to Y.-A. Barde and M. Sefton for useful scientific comments, to J. M. Cosgaya for help in performing the Schwann cell cultures, to $M$. Chao for the gift of the anti-p $75^{\mathrm{ICD}}$ antiserum (9992), anti-p75 ${ }^{\mathrm{ECD}}$ antiserum (9651), and the anti-SC1 antiserum, and to P. Barker for the gift of the anti-NRH2 antiserum.

Correspondence should be addressed to José M. Frade, Instituto Cajal, Consejo Superior de Investigaciones Científicas, Avenida Doctor Arce 37, E-28002 Madrid, Spain. E-mail: frade@cajal.csic.es.

DOI:10.1523/JNEUROSCI.3798-04.2005

Copyright $\odot 2005$ Society for Neuroscience $\quad$ 0270-6474/05/251407-05\$15.00/0 for Western blots) and the affinity-purified antiserum against the $\mathrm{C}$ terminus of SC-1 (used at $4 \mu \mathrm{g} / \mathrm{ml}$ ) were kindly provided by Moses Chao (New York University, New York, NY). The anti-human p75 ${ }^{\mathrm{ICD}}$ polyclonal antiserum (diluted 1:500; Promega, Madison, WI) also revealed nuclear staining in response to NGF (data not shown). The antineurotrophin receptor homolog 2 (NRH2) antiserum (kindly provided by Phil Barker, McGill University, Montreal, Québec, Canada) was diluted 1:800 (immunocytochemistry), diluted 1:5000 (immunodepletion), or diluted 1:10,000 (Western blotting). The amyloid precursor protein (APP)-specific monoclonal antibody 22C11 (Chemicon, Hampshire, UK) was used at $5 \mu \mathrm{g} / \mathrm{ml}$. The $\gamma$-secretase inhibitor $N$-[N-(3,5difluorophenacetyl)-L-alanyl]-( $S$-phenylglycine t-butyl ester (DAPT) was used at $1 \mu \mathrm{M}$, the metalloproteinase inhibitor TNF- $\alpha$ protease inhibitor-2 (TAPI-2) was used at $20 \mu \mathrm{M}$, and the metalloproteinase inhibitor GM 6001 was used at $10 \mu \mathrm{M}$ (all purchased from Calbiochem, La Jolla, CA). PMA was used at $100 \mathrm{ng} / \mathrm{ml}$. Human recombinant NGF- $\beta$, BDNF, and NT3 were stored at $10 \mathrm{ng} / \mu \mathrm{l}$ in $\mathrm{PBS} / 0.5 \%$ bovine serum albumin and were used at $100 \mathrm{ng} / \mathrm{ml}$ unless otherwise stated. TrkB receptor bodies (human TrkB/Fc chimera; R \& D Systems, Abingdon, UK) were used at $1 \mu \mathrm{g} / \mathrm{ml}$.

Reverse transcription-PCR. Amplification of cDNAs derived from RN22-SCs, postnatal day 2 (P2) rat brain, or P2 rat cortex was performed using standard procedures. The PCR primers used were as follows: GAPDH (base pairs 502-521, 1101-1120; GenBank accession number X02231), TrkB (base pairs 852-871, 1569-1588; GenBank accession number M55291), TrkC (base pairs 266-285, 766-785; GenBank accession number L03813), NGF (base pairs 655-674, 973-992; GenBank accession number M36589), BDNF (base pairs 564-583, 745-764; GenBank accession number M61178), and NT3 (base pairs 773-792, 10321051; GenBank accession number NM_031073). TrkB/TrkC primers are specific for both full-length and truncated forms.

Cell culture. RN22-SCs were maintained at $37^{\circ} \mathrm{C}$ in DMEM/10\% FCS (Invitrogen, Carlsbad, CA). For most experiments, RN22-SCs (10,000 cells $/ \mathrm{cm}^{2}$ ) were initially cultured for $24 \mathrm{~h}$ in DMEM, whereas RN22-SCs expressing human APP were cultured in DMEM/10\% FCS. Schwann cells from P2 mouse sciatic nerves were isolated as described by Chan et al. (2000), and they were cultured $\left(10,000 \mathrm{cells} / \mathrm{cm}^{2}\right)$ for $15 \mathrm{~h}$ in DMEM containing $2 \mu \mathrm{M}$ forskolin and bovine pituitary extract (BPE) diluted 
1:100. Cell death was determined using the In Situ Cell Death Detection kit (Hoffman-La Roche, Basel, Switzerland).

Immunocytochemistry. Cells were fixed with $4 \%$ paraformaldehyde ( $15 \mathrm{~min}$ ). Immunostaining was performed following a protocol described previously (López-Sánchez et al., 2005). Nuclei were counterstained with $1 \mu \mathrm{g} / \mathrm{ml}$ propidium iodide or bisbenzimide.

Cell fractionation. All of the steps were performed at $4^{\circ} \mathrm{C}$. Cells were lysed in cytoplasmic buffer (CB) (10 mм HEPES, pH 7.6, $60 \mathrm{~mm} \mathrm{KCl,}$ $1 \mathrm{~mm}$ EDTA, $0.075 \%$ Triton X-100, 1 mM DLdithiothreitol, and $1 \times$ protease inhibitor mixture) and homogenized by passing them through a 22 ga needle. The nuclei were spun down at $325 \times g$ for $4 \mathrm{~min}$, and the supernatant was isolated (cytoplasmic fraction). The pellets were washed with $\mathrm{CB}$ without detergent and extracted in nuclear buffer $(20 \mathrm{~mm}$ Tris- $\mathrm{HCl}$, pH 8.0, $420 \mathrm{~mm} \mathrm{NaCl}, 1.5 \mathrm{~mm} \mathrm{MgCl}_{2}, 0.2 \mathrm{~mm}$ EDTA, 25\% glycerol, and $1 \times$ protease inhibitor mixture). NRH2 immunodepletion of nuclear fractions was performed in $50 \mathrm{~mm}$ Tris- $\mathrm{HCl}, \mathrm{pH}$ 8.0, $168 \mathrm{~mm} \mathrm{NaCl}, 0.6 \mathrm{~mm} \mathrm{MgCl}_{2}, 0.08 \mathrm{~mm}$ EDTA, $10 \%$ glycerol, and $0.1 \%$ Triton X-100. Removal of anti-NRH2 was performed with protein G-agarose beads diluted 1:25 (Santa Cruz Biotechnology, Santa Cruz, CA). Conditioned media $(7.5 \mathrm{ml})$ were concentrated using Centriprep YM-30 (Millipore, Bedford, MA). Total extracts were obtained by cell solubilization in Laemli's buffer.

Western blot. Total extracts (equivalent to 200,000 cells), nuclear and cytoplasmic extracts (15 $\mu \mathrm{g}$ of protein), or concentrated conditioned media (equivalent to $330 \mu \mathrm{l}$ of original culture media) were separated by SDS-PAGE on $11 \%$ acrylamide gels under nonreducing conditions and transferred to Immun-Blot polyvinylidene difluoride membranes (Bio-Rad, Hercules, CA). APPconditioned media $(20 \mu \mathrm{l})$ were separated on $8 \%$ acrylamide gels. Membranes were blocked in 5\% nonfat dried milk in PBS with $0.1 \%$ Tween 20 (PBTw) for $1 \mathrm{~h}$ and incubated overnight at $4^{\circ} \mathrm{C}$ with the antisera in blocking buffer. After being washed five times in PBTw, the membranes were incubated with goat anti-rabbit HRP-conjugated antibody (Jackson ImmunoResearch, West Grove, PA) diluted 1:50,000 in blocking buffer $(1 \mathrm{~h})$ and washed as above. Protein bands were visualized using ECL (Amersham Biosciences, Piscataway, NJ). The films were scanned, and the relative optical density (ROD) of the bands was determined using the Analytical Imaging Station (AIS) 4.0 (Imaging Research, St. Catharines, Ontario, Canada). ROD values were normalized to the value of the protein bands from the control cultures.

Cell counting. Cells were examined by confocal microscopy to define the subcellular localization of the immunostaining using a Leica (Nussloch, Germany) TCF-4D confocal setup. Cell counting was performed with a Nikon (Melville, NY) E80i microscope with phase contrast and epifluorescence illumination. In other experiments, randomly selected fields containing cells counterstained with bisbenzimide were digitalized using a DXM1200F camera (Nikon), and the ROD for $\mathrm{p} 75^{\mathrm{ICD}}$ immunostaining was measured with AIS 4.0. The average ROD value of the cytoplasm defined the threshold that was used under all of the experimental conditions to identify those cells with stronger nuclear labeling for $\mathrm{p} 75^{\mathrm{ICD}}$. This approach yielded results similar to those obtained by direct visual counting (data not shown). On average, 500 cells were analyzed per coverslip.

Statistical analysis. Quantitative data are shown as the mean \pm SEM from $n$ independent experiments. Statistical differences were analyzed using the Student's $t$ test.
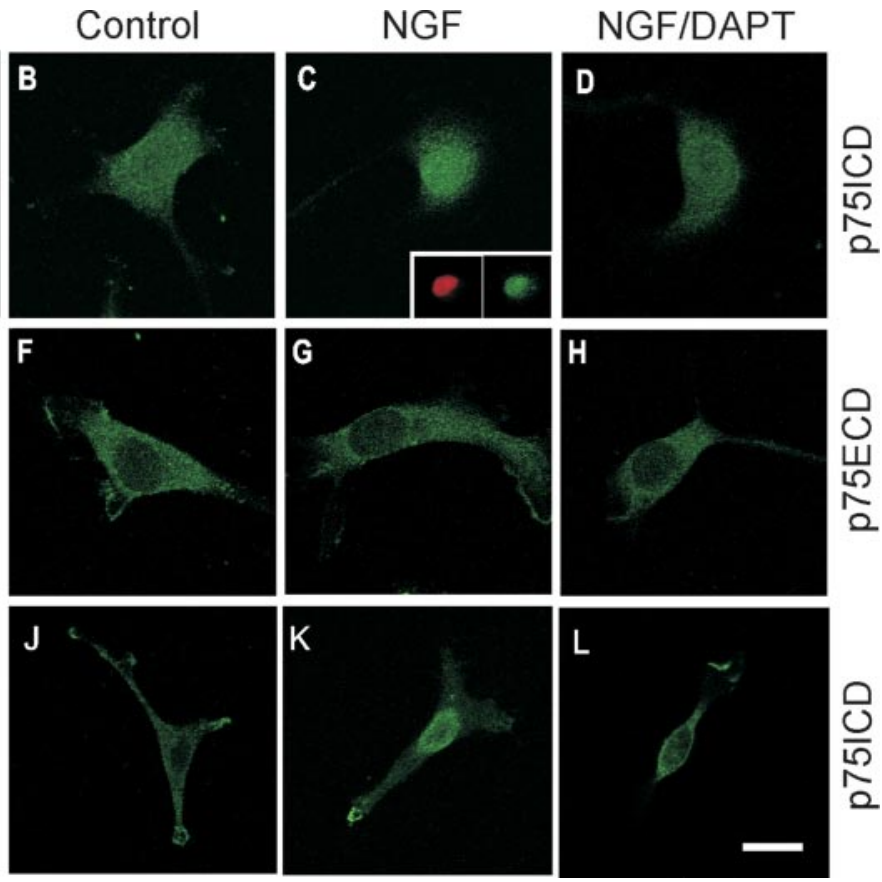

Figure 1. NGF induces nuclear translocation of $\mathrm{p} 75^{\mathrm{ICD}}$ as revealed by immunocytochemistry. $A-H, \mathrm{RN} 22-\mathrm{SCS}$ cultured in the presence $(A)$ or absence $(B-H)$ of FCS were treated for $1 \mathrm{~h}$ with vehicle $(B, F), \mathrm{NGF}(C, G)$, DAPT, or both $(D, H)$ and then were

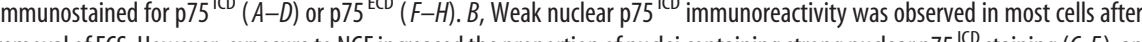
increased in the presence of NGF $(I, K)$, whereas exposure to DAPT prevented this effect of NGF $(I, L) .{ }^{* * *} p<0.001$. Scale bar: $A-D$, $F-H, 14 \mu \mathrm{m} ; J-L, 10 \mu \mathrm{m}$. Cont, Control. Error bars represent SEM.

\section{Results}

NGF induces nuclear translocation of $\mathrm{p} 75^{\mathrm{ICD}}$ in serum-free cultured RN22-SCs

The SC line RN22 lacks the NGF-specific neurotrophic receptor TrkA but contains high levels of p $75^{\text {NTR }}$ (Gentry et al., 2000). The cellular distribution of $\mathrm{p} 75^{\mathrm{ICD}}$ was determined in these cells by immunocytochemistry, and laser-scanning confocal microscopy confirmed that, in the presence of FCS, p75 ${ }^{\mathrm{ICD}}$ did not accumulate in the nucleus (Fig. 1A) (Kanning et al., 2003). However, in the absence of serum, the intensity of $\mathrm{p} 75^{\mathrm{ICD}}$ labeling in the majority of nuclei was equivalent to or less than that in the cytoplasm (Fig. $1 \mathrm{~B}$ ). In the presence of NGF, a considerable accumulation of p $75^{\mathrm{ICD}}$ occurred in $\sim 70 \%$ of nuclei, in contrast to control cells, in which only $\sim 20 \%$ of the nuclei were strongly labeled for p75 ${ }^{\mathrm{ICD}}$ (Fig. 1C,E). The increase in the proportion of nuclei strongly labeled for $\mathrm{p} 75^{\mathrm{ICD}}$ was observed $10 \mathrm{~min}$ after the addition of NGF (Fig. 2A) and lasted for at least $24 \mathrm{~h}$ (data not shown). The half-maximal effect of NGF was attained after 2-3 min. The proportion of nuclei strongly labeled for $\mathrm{p} 75^{\mathrm{ICD}}$ increased in a concentration-dependent manner, with $\sim 5-10$ ng/ml NGF producing a half-maximal effect (Fig. $2 B$ ). Exposure to DAPT prevented the increase in the proportion of nuclei that accumulated high levels of $\mathrm{p} 75^{\mathrm{ICD}}$ in response to NGF (Fig. $1 D, E)$. Hence, the ligand-dependent release of $\mathrm{p} 75^{\mathrm{ICD}}$ seems to require $\gamma$-secretase activity. As expected, p $75^{\mathrm{ECD}}$ immunolabeling was absent from the nucleus, regardless of the presence or absence of NGF or DAPT (Fig. $1 F-H$ ).

To confirm that the $\mathrm{p} 75^{\mathrm{ICD}}$ does indeed accumulate in the nucleus in response to NGF, nuclear and cytoplasmic extracts 

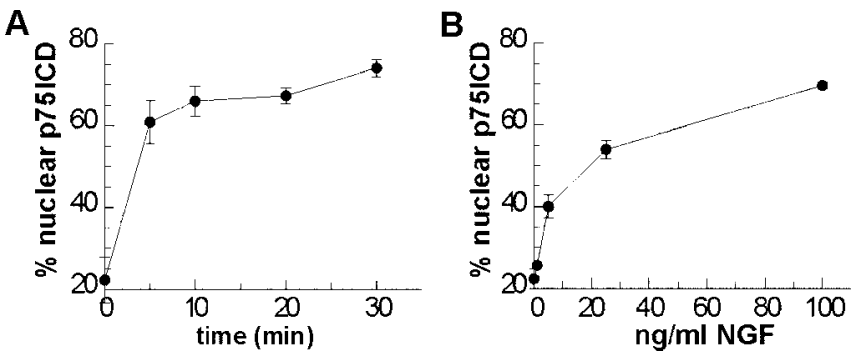

Figure 2. Time course and dose-response of the NGF-induced nuclear translocation of $\mathrm{p} 75^{\mathrm{ICD}}$. A, Percentage of RN22-SC nuclei with strong $\mathrm{p} 75^{\mathrm{ICD}}$ immunoreactivity when cultured in the presence of NGF for the time periods indicated. $B$, Percentage of RN22-SC nuclei with strong p $75^{\mathrm{ICD}}$ immunoreactivity in cells cultured for $24 \mathrm{~h}$ in the presence of the concentrations of NGF indicated. Error bars represent SEM.

were subjected to Western blotting with a $\mathrm{p} 75^{\mathrm{ICD}}$-specific antiserum. A $25 \mathrm{kDa}$ band, characterized previously as p75 ${ }^{\mathrm{ICD}}$ (Jung et al., 2003; Kanning et al., 2003), was enriched in nuclear extracts from RN22-SCs exposed to NGF for $2 \mathrm{~h}(n=2)$ (Fig. $3 A)$. In the presence of the $\gamma$-secretase inhibitor DAPT, the levels of this protein diminished to those of control cells. Additional protein bands of 28,33 , and $37 \mathrm{kDa}$ were observed in these extracts, but they remained at a similar intensity under all of the conditions (Fig. 3A). These bands are likely to represent NRH2 moieties that cross-react with the anti-p $75^{\mathrm{ICD}}$ antiserum because they were also detected with the NRH2-specific antiserum $(n=2)$ (Fig. $3 A$ ). Immunodepletion with this anti-NRH2 antiserum allowed us to unambiguously identify the $25 \mathrm{kDa}$ band corresponding to p75 ${ }^{\mathrm{ICD}}$ in the nuclear extracts from RN22-SCs (Fig. 3A). Densitometric analysis demonstrated that this band was significantly increased in the NGF-treated cultures, an increase that was prevented by DAPT [control, 1; NGF, $9.63 \pm 1.88(p<0.01)$; DAPT, $0.74 \pm 0.25 ;$ DAPT/NGF, $1.57 \pm 0.10 ; n=3]$.

In the cytoplasmic fractions, the $\mathrm{p} 75^{\mathrm{ICD}}$-specific antiserum only detected the full-length p $75^{\mathrm{NTR}}$ protein (Fig. $3 A$ ). Interestingly, the intensity of the full-length protein was reduced in the fraction obtained from the NGF-treated cells, in accordance with the cleavage and nuclear translocation of $\mathrm{p} 75^{\mathrm{ICD}}$, and this decrease was blocked in the presence of DAPT [control, 1; NGF, $0.45 \pm 0.01(p<0.001)$; DAPT, $1.24 \pm 0.03$; DAPT/NGF, $1.14 \pm$ $0.02 ; n=2]$. No higher-mobility bands corresponding to the p $75^{\text {NTR }}$ C-terminal domain were observed in the cytoplasmic fraction, even in the presence of DAPT. Thus, the release of p75 ${ }^{\mathrm{ICD}}$ in response to NGF does not seem to require the previous shedding of the ectodomain attributable to $\alpha$-secretase activity. Alternatively, NGF might induce $\alpha$-secretase cleavage and the release of the $\mathrm{p} 75^{\mathrm{NTR}}$ extracellular domain, but immunoblotting may not be sufficiently sensitive to detect the C-terminal fragment in the presence of DAPT.

To discriminate between these two alternatives, total cell extracts were subjected to Western blotting with the $\mathrm{p} 75^{\mathrm{ICD}}$ specific antiserum (Fig. $3 B$ ). This analysis confirmed that NGF induces the accumulation of a faint $25 \mathrm{kDa}$ band, and this effect is blocked by DAPT. No high-mobility bands specific for the p $75^{\text {NTR }}$ C-terminal domain were observed in extracts from cells treated with NGF and DAPT, thus indicating that the release of p $75^{\text {ICD }}$ does not seem to require two cleavage steps.

To study further whether the activation of $\alpha$-secretase is necessary for the release of $\mathrm{p} 75^{\mathrm{ICD}}$ provoked by NGF, culture media conditioned by RN22-SCs were analyzed in Western blots using the anti-p75 ${ }^{\mathrm{ECD}}$ antiserum (Fig. $3 \mathrm{C}$ ). A protein of $55 \mathrm{kDa}$ was identified in medium conditioned by NGF-treated cells but not in medium from control cells. This protein was slightly larger than the $50 \mathrm{kDa}$ p $75^{\mathrm{NTR}}$ ectodomain released by $\alpha$-secretase in response to PMA in the presence of serum $(n=2)$ (Weskamp et al., 2004) (Fig. 3C) and could represent the complete p $75^{\text {NTR }}$ ectodomain cleaved by $\gamma$-secretase. In agreement with this idea, the intensity of this band in the medium conditioned by cells treated with NGF was dramatically reduced by the presence of DAPT [NGF, 1 ; DAPT/NGF, $0.08 \pm 0.06(p<0.05) ; n=3$ ] (Fig. $3 C)$. These data strongly suggest that the interaction of NGF with p $75^{\text {NTR }}$ results in $\gamma$-secretase cleavage of p $75^{\text {NTR }}$ without the previous activation of $\alpha$-secretase. Moreover, it seems that matrix metalloproteinases are not involved in the $\gamma$-secretase cleavage of p $75^{\text {NTR }}$. In the presence of TAPI-2, an inhibitor of matrix metalloproteinases that prevents PMA-dependent shedding of $\mathrm{p} 75^{\mathrm{NTR}}$ (Jung et al., 2003; Kanning et al., 2003; Weskamp et al., 2004), the proportion of RN22-SC nuclei strongly labeled for $\mathrm{p} 75^{\mathrm{ICD}}$ when visualized by immunocytochemistry still increased in response to NGF [control, $22.18 \pm 6.09 \%$; NGF, $69.42 \pm 1.57 \%(p<0.005)$; TAPI-2, $24.49 \pm 3.09 \%$; TAPI-2/NGF, $70.48 \pm 1.96 \%(p<$ $0.001) ; n=3$ ]. Likewise, the release of the $\mathrm{p} 75^{\mathrm{NTR}}$ ectodomain in response to NGF was not affected by the presence of TAPI-2 (NGF, 1 ; TAPI-2/NGF, $0.88 \pm 0.12 ; n=2$; nonsignificant) (Fig. $3 D)$. The activity of TAPI-2 under these conditions was confirmed by its ability to prevent APP shedding from RN22-SCs expressing human APP [control, 1; TAPI-2, $0.18 \pm 0.03(p<$ 0.005); $n=2$ ] (Fig. 3D). The metalloproteinase inhibitor GM 6001 also failed to prevent the accumulation of $\mathrm{p} 75^{\mathrm{ICD}}$ in the nuclei of the RN22-SCs in response to NGF [control, $28.90 \pm$ 8.80\%; NGF, $73.21 \pm 6.71 \%(p<0.005)$; GM 6001, $20.19 \pm$ 5.16\%; GM 6001/NGF, $85.24 \pm 0.69 \%(p<0.001) ; n=4]$.

To determine whether $\mathrm{p} 75^{\mathrm{ECD}}$ can also accumulate in the cytoplasm in response to NGF, the cytoplasmic fractions of RN22-SCs cultured with different combinations of NGF and DAPT were analyzed by Western blot using the $\mathrm{p} 75^{\mathrm{ECD}}$-specific antiserum. These cytoplasmic fractions did not contain the 55 $\mathrm{kDa} p 75^{\mathrm{ECD}}$ but rather the full-length $\mathrm{p} 75^{\mathrm{NTR}}$, which was less intense in the extracts obtained from NGF-treated cells than in control cells [control, 1; NGF, $0.34 \pm 0.03(p<0.005)$; DAPT, $0.97 \pm 0.15$; DAPT/NGF, $1.17 \pm 0.05 ; n=2$ ] (Fig. $3 C$ ). A $28 \mathrm{kDa}$ protein band was also observed after all of the treatments, which may be attributable to nonspecific binding, or it may correspond to a degradation product of $\mathrm{p} 75^{\mathrm{ECD}}$. This band might account for the strong staining for $\mathrm{p} 75^{\mathrm{ECD}}$ observed in the cytoplasm of NGFtreated cells (Fig. $1 G$ ).

\section{NGF induces nuclear translocation of $\mathrm{p} 75^{\mathrm{ICD}}$ in \\ Schwann cells}

We determined whether the nuclear accumulation of $\mathrm{p} 75^{\mathrm{ICD}}$ in response to NGF might occur in nontransformed cells. In Schwann cells derived from P2 mice grown in DMEM supplemented with FCS, p75 ${ }^{\mathrm{ICD}}$ did not accumulate in the nuclei (data not shown). However, in the presence of forskolin and BPE, 5\% of the nuclei contained p75 ICD (Fig. $1 \mathrm{I}$ ). Moreover, in the presence of NGF, the proportion of $\mathrm{p} 75^{\mathrm{ICD}}$-immunoreactive nuclei increased to $\sim 25 \%$, (Fig. $1 I, K$ ). The effect of NGF on the nuclear accumulation of $\mathrm{p} 75^{\mathrm{ICD}}$ was inhibited by the addition of DAPT (Fig. $1 I, L)$. Hence, the activation of $\mathrm{p} 75^{\mathrm{NTR}}$ by NGF seems to provoke regulated intramembrane proteolysis (RIP) and the nuclear translocation of $\mathrm{p} 75^{\mathrm{ICD}}$ in primary cell cultures.

\section{BDNF and NT3 also induce nuclear translocation of $\mathrm{p} 75^{\mathrm{ICD}}$}

The possibility that other neurotrophins could induce nuclear accumulation of $\mathrm{p} 75^{\mathrm{ICD}}$ was also evaluated in RN22-SCs. Be- 
cause these cells do not express either TrkB or $\operatorname{TrkC}$ (Fig. $4 F$ ), any interference of these BDNF- and NT3-specific tyrosine kinase receptors with the signaling of $\mathrm{p} 75^{\mathrm{NTR}}$ was avoided. Both BDNF and NT3 increased the proportion of cells showing strong nuclear $\mathrm{p} 75^{\mathrm{ICD}}$ immunoreactivity in a manner similar to NGF (Fig. $4 A-D$ ). These data indicate that all of the neurotrophins have a similar capacity to induce $\mathrm{p} 75^{\mathrm{ICD}}$ release and nuclear translocation.

We tested whether RN22-SCs cultured in the absence of serum express NGF, BDNF, or NT3. BDNF expression could be detected by reverse transcription (RT)PCR in cDNAs derived from these cells (Fig. $4 E$ ). This suggests that the presence of endogenous BDNF in the culture medium during the $24 \mathrm{~h}$ period before the treatment with NGF could be responsible for the $20 \%$ of nuclei strongly stained with the anti-p75 ICD antiserum under control conditions (Fig. 1E). Indeed, the addition of DAPT at the time of serum withdrawal strongly reduced the background levels of cells with strong nuclear p $75^{\text {ICD }}$ immunoreactivity $[1.17 \pm 0.19 \%(p<0.001) ; n=$ 4]. Blockage of endogenous BDNF with the addition of $\mathrm{TrkB}$ receptor bodies at the time of serum withdrawal $(1 \mu \mathrm{g} / \mathrm{ml})$ also reduced the proportion of nuclei with high levels of p $75^{\mathrm{ICD}}$ immunoreactivity [8.69 \pm $0.21 \%(p<0.005) ; n=4]$. This indicates that, during the period in which the RN22SCs are initially cultured in the absence of serum, p $75^{\text {ICD }}$ accumulates in the nucleus in response to ligand-mediated, $\gamma$-secretasedependent release of $\mathrm{p} 75^{\mathrm{ICD}}$. This effect seems to be mediated at least partially by BDNF.

\section{Discussion}

In this study, we present evidence that the activation of $\mathrm{p} 75^{\mathrm{NTR}}$ with NGF promoted the release of $\mathrm{p} 75^{\mathrm{ICD}}$ via the activity of $\gamma$-secretase. We show that the increased accumulation of p $75^{\text {ICD }}$ in the nuclei of RN22-SCs or Schwann cells in the presence of NGF was impaired by the $\gamma$-secretase inhibitor DAPT. Furthermore, the detection of a p $75^{\mathrm{ICD}}$-specific protein band in the nuclear and total cell extracts from RN22-SCs treated with NGF was also inhibited by DAPT. Finally, Western blot analysis indicated that the levels of full-length $\mathrm{p} 75^{\mathrm{NTR}}$ were reduced in the cytoplasmic and total cell extracts of RN22-SCs treated with NGF, suggesting that $\mathrm{p} 75^{\mathrm{ICD}}$ is released after neurotrophin binding. This effect was also reversed by DAPT.

p $75^{\text {ICD }}$ accumulation in the nucleus was dependent on the concentration of NGF and was completed in $<10 \mathrm{~min}$. This rapid activation of $\gamma$-secretase has also been seen in other RIP paradigms (Ray et al., 1999). Furthermore, the rapid response of p $75^{\text {NTR }}$ is not unique because the association of TRAF6 (TNF receptor-associated factor 6) with $\mathrm{p} 75^{\mathrm{NTR}}$ occurs $1 \mathrm{~min}$ after NGF treatment and also reaches a maximum after $10 \mathrm{~min}$ (Khursigara et al., 1999). In contrast, internalization of $\mathrm{p} 75^{\mathrm{NTR}}$ in response to neurotrophins is much slower, taking $\sim 45 \mathrm{~min}$ (Bron- $\begin{array}{ll}\text { DAPT } & \alpha \text { NRH2 } \\ \text { INGF } & \text { Control }\end{array}$

.

C

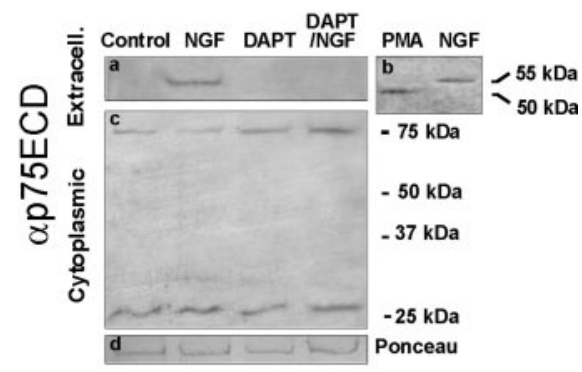

D

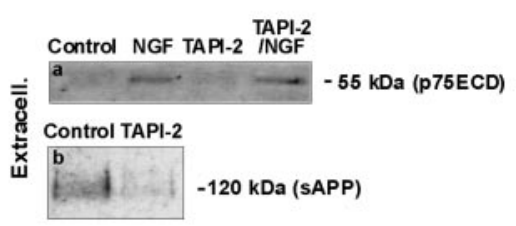

Figure 3. NGF induces $p 75^{\mathrm{ECD}}$ shedding and nuclear accumulation of $\mathrm{p} 75^{\mathrm{ICD}}$ independent of metalloproteinases. $A a$, Nuclear ( as a $25 \mathrm{kDa}$ band in the NGF-treated cells (asterisk), an effect that was prevented by DAPT. Ab, The 28, 33, and $37 \mathrm{kDa}$ bands served in these extracts were also recognized by the NRH2-specific antiserum. $A d$, The $\mathrm{p}^{2} 5^{\mathrm{ICD}}$-specific band was clearly ob$\mathrm{Ca}$, The anti-p $75^{\mathrm{ECD}}$ antiserum recognized a single $55 \mathrm{kDa}$ band in the culture medium conditioned for $24 \mathrm{~h}$ by cells treated with NGF. The intensity of this band was reduced in the presence of DAPT, and it was distinct from that released in response to PMA by

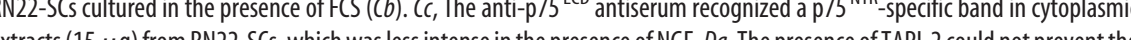
release of $p 75^{\mathrm{ECD}}$ from cells cultured in the presence of NGF as detected with the anti-p $75^{\mathrm{ECD}}$ antiserum. However, TAPI-2 did pres solding of soluble APP in RN22-SCs expressing human APP $(D b)$. See Results for quantification of the intensity of the bands and statistical analysis. The amount of nuclear or cytoplasmic protein on the membranes per lane was similar in all of the experiments as revealed by Ponceau $S$ staining $(A c, A e, A g, B, C d)$. Extracell., Extracellular.

fman et al., 2003). This suggests that the release of $\mathrm{p} 75^{\mathrm{NTR}}$ does not need a previous internalization step and that it can take place directly at the cell surface. It is unclear why neurotrophindependent RIP of p75 ${ }^{\text {NTR }}$ was only observed when RN22-SCs were cultured in serum-free medium. Schwann cells grown in the presence of serum, forskolin, and BPE showed a similar, although less pronounced, effect in response to NGF. It is possible that protein kinase A (PKA), an indirect target of forskolin, might sensitize Schwann cells to undergo RIP in response to NGF. Indeed, PKA has been shown to be necessary for TNF receptor-1 shedding (Douvdevani et al., 1996).

The capacity of $\mathrm{p} 75^{\mathrm{NTR}}$ to translocate its intracellular domain to the nucleus in response to ligand activation resembles the pathway used by Notch or ErbB-4 to transduce intracellular signals (Ebinu and Yankner, 2002). Unlike these receptors, p75 NTR seems to undergo ligand-dependent RIP in the absence of $\alpha$-secretase-dependent ectodomain shedding. This conclusion was based first on the failure to detect the C-terminal p $75^{\text {NTR }}$ fragment derived from ectodomain shedding of the receptor in the cytoplasmic and total cell extracts from NGF-treated RN22SCs cultured in the presence of DAPT. Moreover, the p75 ECD released in response to $\mathrm{NGF}$ as a $55 \mathrm{kDa}$ fragment is larger than the $\mathrm{p} 75^{\mathrm{NTR}}$ ectodomain released by $\alpha$-secretase (Weskamp et al., 

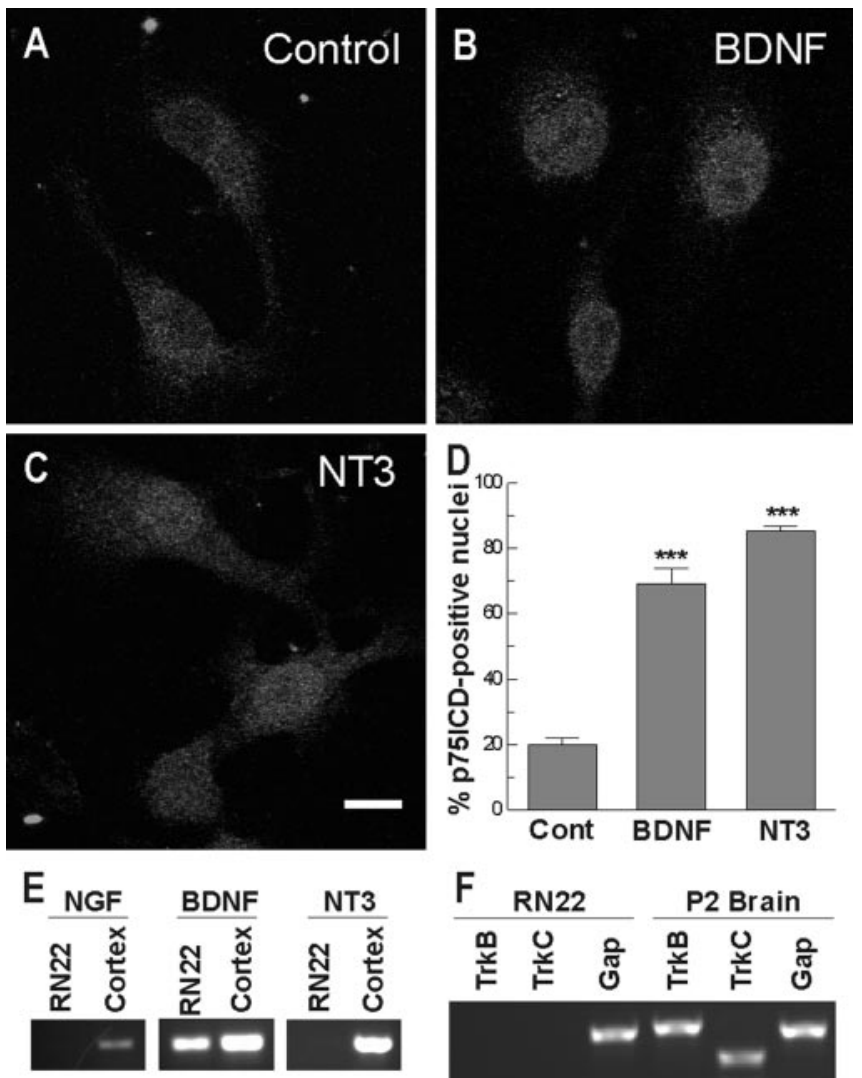

Figure 4. Both BDNF and NT3 also induce nuclear translocation of $p 75^{\mathrm{ICD}} \cdot B-D$, Treatment of RN22-SCs for $1 \mathrm{~h}$ with $100 \mathrm{ng} / \mathrm{ml} \mathrm{BDNF}(B)$ or NT3 ( $C$ ) increased the proportion of nuclei with strong p75 ${ }^{\mathrm{ICD}}$ staining $(B-D)$ when compared with control (Cont) cells $(A, D)$. E, Expression of $N G F, B D N F$, and NT3 was analyzed by RT-PCR (38 cycles) on mRNA from RN22-SCs (RN22) or P2 rat cortex (Cortex). BDNF expression could be detected in RN22-SCs. F, Expression of TrkB, TrkC, and GAPDH (Gap) was analyzed by RT-PCR (35 cycles) on total mRNA derived from RN22-SCs or $\mathrm{P} 2$ rat brain (P2 Brain). TrkB- and TrkC-specific transcripts could not be detected in RN22-SCs. In the absence of reverse transcription, no amplification was detected for any of these genes (data not shown). ${ }^{* *} p<0.001$. Scale bar, $10 \mu \mathrm{m}$. Error bars represent SEM.

2004; this study), and blocking $\gamma$-secretase activity prevented the NGF-dependent release of this $55 \mathrm{kDa}$ ectodomain fragment. Finally, the metalloproteinase inhibitors TAPI-2 and GM 6001 were both unable to reduce the proportion of nuclei with high levels of $\mathrm{p} 75^{\mathrm{ICD}}$ in RN22-SCs treated with NGF, and TAPI-2 could not prevent the release of the $55 \mathrm{kDa}$ ectodomain fragment. This novel behavior of $\mathrm{p} 75^{\mathrm{NTR}}$ suggests that neurotrophin binding provokes conformational changes in its transmembrane domain necessary for $\gamma$-secretase cleavage.

In RN22-SCs grown with FCS, p75 ${ }^{\mathrm{ICD}}$ was only observed in cell extracts in the presence of proteasome inhibitors (Kanning et al., 2003). Here, endogenously expressed $\mathrm{p} 75^{\mathrm{ICD}}$ was detected in FCS-depleted RN22-SCs without the need for proteasome inhibitors. One explanation for the stability of $\mathrm{p} 75^{\mathrm{ICD}}$ in the absence of FCS is that it may interact with proteins that stabilize it, as occurs with Notch and APP (Kimberly et al., 2001). One such protein that interacts with $\mathrm{p} 75^{\mathrm{ICD}}$ is Schwann cell factor 1 (SC1), which is located in the nucleus in the absence of FCS (Chittka and Chao, 1999). Indeed, we detected nuclear SC1 in RN22-SCs cultured in the absence of serum (data not shown), consistent with the possibility that SC1 stabilizes p $75^{\mathrm{ICD}}$ in the nucleus of these cells.

The analysis of the nuclear fraction by Western blotting with the anti-p $75^{\mathrm{ICD}}$-specific antiserum identified the presence of 28 , 33 , and $37 \mathrm{kDa}$ bands, whose intensity was not affected by the experimental manipulations. These bands were probably the result of a cross-reaction with NRH2 because they were detected by a well characterized anti-NRH2 antiserum (Paul et al., 2004) Moreover, they were absent in the NRH2-immunodepleted nuclear fractions analyzed with the anti-p $75^{\mathrm{ICD}}$ antiserum. For unknown reasons, the NRH2-specific bands were not detected by the $\mathrm{p} 75^{\mathrm{ICD}}$ antiserum in total cell extracts, as described previously by Murray et al. (2004).

\section{References}

Bronfman FC, Tcherpakov M, Jovin TM, Fainzilber M (2003) Ligandinduced internalization of the p75 neurotrophin receptor: a slow route to the signaling endosome. J Neurosci 23:3209-3220.

Chan JR, Rodriguez-Waitkus PM, Ng BK, Liang P, Glaser M (2000) Progesterone synthesized by Schwann cells during myelin formation regulates neuronal gene expression. Mol Biol Cell 11:2283-2295.

Chittka A, Chao MV (1999) Identification of a zinc finger protein whose subcellular distribution is regulated by serum and nerve growth factor. Proc Natl Acad Sci USA 96:10705-10710.

Douvdevani A, Einbinder T, Yulzari R, Rogachov B, Chaimovitz C (1996) TNF-receptors on human peritoneal mesothelial cells: regulation of receptor levels and shedding by IL-1 alpha and TNF alpha. Kidney Int 50:219-228.

Ebinu JO, Yankner BA (2002) A RIP tide in neuronal signal transduction. Neuron 34:499-502.

Gentry JJ, Casaccia-Bonnefil P, Carter BD (2000) Nerve growth factor activation of nuclear factor $\kappa \mathrm{B}$ through its $\mathrm{p} 75$ receptor is an anti-apoptotic signal in RN22 schwannoma cells. J Biol Chem 275:7558-7565.

Jung KM, Tan S, Landman N, Petrova K, Murray S, Lewis R, Kim PK, Kim DS, Ryu SH, Chao MV, Kim TW (2003) Regulated intramembrane proteolysis of the p75 neurotrophin receptor modulates its association with the TrkA receptor. J Biol Chem 278:42161-42169.

Kanning KC, Hudson M, Amieux PS, Wiley JC, Bothwell M, Schecterson LC (2003) Proteolytic processing of the p75 neurotrophin receptor and two homologs generates C-terminal fragments with signaling capability. J Neurosci 23:5425-5436.

Khursigara G, Orlinick JR, Chao MV (1999) Association of the p75 neurotrophin receptor with TRAF6. J Biol Chem 274:2597-2600.

Kimberly WT, Zheng JB, Guenette SY, Selkoe DJ (2001) The intracellular domain of the $\beta$-amyloid precursor protein is stabilized by Fe65 and translocates to the nucleus in a notch-like manner. J Biol Chem 276:40288-40292.

López-Sánchez N, Frade JM (2002) Control of the cell cycle by neurotrophins: lessons from the p75 neurotrophin receptor. Histol Histopathol 17:1227-1237.

López-Sánchez N, Müller U, Frade JM (2005) Lengthening of G2/mitosis in cortical precursors from mice lacking $\beta$-amyloid precursor protein. Neuroscience 130:51-60.

Murray SS, Perez P, Lee R, Hempstead BL, Chao MV (2004) A novel p75 neurotrophin receptor-related protein, $\mathrm{NRH} 2$, regulates nerve growth factor binding to the TrkA receptor. J Neurosci 24:2742-2749.

Paul CE, Vereker E, Dickson KM, Barker PA (2004) A pro-apoptotic fragment of the p75 neurotrophin receptor is expressed in p75NTR ${ }^{\text {ExonIV }}$ null mice. J Neurosci 24:1917-1923.

Ray WJ, Yao M, Mumm J, Schroeter EH, Saftig P, Wolfe M, Selkoe DJ, Kopan R, Goate AM (1999) Cell surface presenilin-1 participates in the gammasecretase-like proteolysis of Notch. J Biol Chem 274:36801-36807.

Weskamp G, Schlöndorff J, Lum L, Becherer JD, Kim TW, Saftig P, Hartmann D, Murphy G, Blobel CP (2004) Evidence for a critical role of the tumor necrosis factor $\alpha$ convertase (TACE) in ectodomain shedding of the p75 neurotrophin receptor (p75 $\left.{ }^{\mathrm{NTR}}\right)$. J Biol Chem 279:4241-4249. 